\title{
LOS CERVANTES DE AMÉRICO CASTRO
}

$\mathrm{Al}$ aceptar la invitación del Instituto Cervantes a participar en este coloquio sobre $\ll \mathrm{El}$ Quijote, taller de existencialidad» y, más concretamente, en el de «Cervantes y los casticismos españoles», a partir del análisis de la obra cervantina desde el prisma de Américo Castro, lo he hecho con cierta incomodidad, originada por la sensación de haber dicho ya lo que podía decir sobre el tema. En numerosos ensayos y artículos, he expuesto la aportación fundamental del autor de Cristianos, moros y judios al conocimiento de la obra de nuestro primer escritor, fundador, con Rabelais, de la novela moderna, y me agobia la sensación de reiterarme. Como suelo decir a quienes me invitan a reuniones y conferencias del corte de las que les leo, los políticos y especialistas en homenajes y celebraciones pueden y deben repetirse, pero los escritores, no. Y lo que yo pueda decir de mi infinita deuda con Cervantes se expresa mejor en mis novelas que en charlas y mesas redondas.

Como los escritores de un mundo literario sin fronteras nacionales que más aprecio, cervanteo a sabiendas o sin saberlo. Parafraseando a Carlos Fuentes, asumo con honra mi verdadera nacionalidad: la cervantina. El linaje literario del Quijote compone un diagrama arbóreo de ramificación infinita. La lista de los «contaminados» poro su invención novelesca abarca no sólo el espacio europeo sino también la del Nuevo Mundo: Fielding, Sterne, Defoe, Diderot, Flaubert, Machado de Asís, Joyce y, en las pasadas décadas, Borges, Gombrowictz, Fuentes, Kundera, Fernando del Paso, Cabrera Infante, Julián Ríos... La novela moderna no existiría sin el Quijote o sería enteramente distinta de la que conocemos. Sus ramificaciones trazan una extraordinaria cartografía que, a través de mares, continentes y océanos, revela los frutos de su poder genérico. El árbol genealógico que parte de Cervantes es el de la evolución del arte novelesco independientemente de todo contexto nacional.

En las aproximaciones sucesivas de Américo Castro al autor del Quijote podemos distinguir grosso modo tres períodos: el anterior a la Guerra Civil y el exilio, esto es, el de El pensamiento de Cervantes; el de los espléndidos ensayos de Hacia Cervantes - muy especialmente «La estructura del Quijote» y «La palabra escrita y el Quijote», en los que me detendré luego-; y el del aguijador y controvertido Cervantes y los casticismos españoles. En realidad, más que de períodos, convendría hablar de ámbitos, pues el segundo y el tercero se entreveran y se complementan desde finales de los cuarenta a la muerte de su autor.

El de El pensamiento de Cervantes, publicado en 1925, es el que me interesa menos. Castro rompió, eso sí, en su libro, con la apropiación nacionalista y patriótica del héroe cervantino por Ganivet y Unamuno - apropiación que revelaría luego los límites de la honestidad intelectual en el caso de García Morente, Ramiro de Maeztu y otros panegiristas del nacionalcatolicismo durante la Cruzada de Franco-, y puso el acento en la cultura humanista del autor y el influjo que ejerció en él el pensamiento erasmista. Con todo, no alcanzó a percibir la novela como una forma artística irreductible a los códigos y modelos literarios anteriores y a señalar así su extraordinaria singularidad, como haría luego en los ensayos antes citados. El mismo reproche afecta a Ortega en sus Meditaciones del Quijote: 
pese a su interés teórico por la evolución del arte novelesco, no se detiene a analizar su estructura insólita y si dinámica interna, privándose con ello de comprender las razones de su frescura e inmarchitable novedad. Fue Manuel Azaña, en una conferencia titulada «Cervantes y la invención del Quijote», que leyó en el club femenino español Lyceum en 1930, quien percibió primero en nuestra lengua la audacia creativa de su conciudadano alcalaíno y analizó esa modernidad atemporal que circula a través de los tiempos, anticipándose así a los estudios magistrales de Bajtin sobre Rabelais y Cervantes.

Me permitiré leer unos pasajes de la conferencia de Azaña en la medida en que enlazan con las observaciones de don Américo en los ensayos antes citados. Vayan de ejemplo estas líneas esclarecedoras sobre la novela cuyo cuarto centenario celebramos:

una gran obra poética [...] nos alumbra y descubre [las maneras de sentir] que nosotros virtualmente poseemos, al modo que la sonda artesana perfora la corteza terrestre y hace surtir un caudal apenas creíble, de tan profundo como era [...]. Esta magia-añade-suscita la posteridad de una obra [...]. No es la posteridad quien descubre, encumbra o sanciona la virtud de una obra, es la obra misma, según sea de fecunda, quien engendra su propia posteridad.

Más adelante, Azaña establece una distinción fundamental entre contemporaneidad y actualidad, distinción que permite reconocer la diferencia entre lo que yo llamo «texto literario» y el «producto editorial»:

Lo contemporáneo-escribe Manuel Azaña-, es, pues, distinto de lo actual, y en cierto sentido incompatible con ello. Lo actual se obtiene mediante cortes verticales en la cinta del tiempo que transcurre. Hoy es actual lo que ayer no lo fue ni lo será mañana. Lo contemporáneo se establece en la dimensión profunda, penetrando de una en otra capa para abrir comunicación entre una sensibilidad personal de hoy y obras y personas de otros días.

Con una aguda percepción de lo que sería más tarde la industria del libro y el influjo devastador de la mercadotecnia en el gusto público, Azaña escribe estas líneas proféticas sobre ese lector ingenuo que

piensa que bajo cada título reciente, el autor, [sic] se rehace; pide-y si no, no paga-obras nuevas o que se lo parezcan, y casi siempre las obtiene, recibiendo por tales las repeticiones de una misma obra con diferente aliño. A Cervantes le hubiese pedido un Quijote con cincuenta partes, y doscientas novelas cortas. Así trató a Lope, quien, como tantos autores modernos, se dejó aupar e idolatrar por el vulgo a fuerza de arrojarle cientos y cientos de obras abortadas.

Después de leer estas observaciones, ¿quién puede calificarle honradamente de «mediocre», como ha hecho, hace poco, en unas desafortunadas declaraciones, un renombrado cervantista?

Pero volvamos a Américo Castro y a su análisis de la novedad del Quijote en el contexto de la evolución de las obras artísticas, tal y como aparece en sus ensayos de Hacia 
Cervantes. En «Lectura cervantina de Tres tristes tigres», la gran novela del escritor cubano Guillermo Cabrera Infante, recientemente fallecido, mostré cómo afloraba paulatinamente en sus páginas ese subyacente esquema del Quijote, como un palimpsesto borrado y rehecho. No se trataba, dije, de un ingenio deliberado ni siquiera consciente, sino de algo más profundo: quienes conciben la novela como una empresa artística, en la que forma y contenido andan indisolublemente unidos, entran en el campo de maniobras de Cervantes. Cito unas líneas del ensayo antes mencionado que figura en Disidencias:

EN SU Vida de don Quijote y Sancho, al llegar al capítulo sexto de la primera parte de la obra, consagrado al escrutinio de la biblioteca del hidalgo por el cura y el barbero, Unamuno lo despacha con estas breves líneas sentenciosas: «Todo lo cual es crítica literaria que debe importarnos muy poco. Trata de libros y no de vida. Pasémoslo por alto» A decir ver, el capítulo sexto desempeña un papel fundamental en la novela, hasta el punto de que sin él el Quijote no existiría. Lo que Unamuno pasó por alto fue, nada menos, la maravillosa galería de espejos cervantina, ese juego a la vez destructivo y creador con los diferentes códigos literarios de su tiempo.

Esto, en cambio, lo vio muy bien Américo Castro cuando escribió:

Se ha hablado mucho de las fuentes literarias del Quijote, y muy poco de la presencia y función de los libros dentro del proceso creador de la obra. Leer o haber leído, escribir o estar escribiendo son tareas de muchos de los personajes que pueblan las páginas del Quijote, tareas sin las cuales no existirían algunos de ellos... Diríamos en vista de ello que el Quijote es un libro forjado y deducido de la activa materia de otros libros. La primera parte emana esencialmente de los libros leídos por don Quijote; la segunda es, a su vez, emanación de la primera, pues no se limita a seguir narrando nuevos sucesos, sino que incorpora en la vida del personaje la conciencia de haber sido aquélla ya narrada en un libro. El don Quijote de la segunda parte se continúa a sí mismo y a la interpretación literaria de Cide Hamete.

De todo ello he tratado en diferentes ensayos y en mis lecturas de la Biblioteca Nacional de Francia en enero de 1998 sobre los posibles semillas de la invención cervantina y la «polinización» posterior de la novela en autores tan diversos como Flaubert, Borges y Günter Grass.

La reivindicación por Américo Castro de la herencia judeoárabe en la cultura española de la Edad Media y del papel desempeñado por los conversos y sus descendientes cristianonuevos en la literatura y el pensamiento peninsular en los siglos XV, XVI y XVII ha hecho correr ríos de tinta. Las afirmaciones supuestamente temerarias del historiador se han convertido con el paso del tiempo en verdades corroboradas por los hechos, aunque la resistencia encarnizada de los misoneístas las mantengo al margen del mundo oficial académico y universitario (vg. la expresión «duelos y quebrantos los sábados». La bibliografía tocante al linaje de Cervantes y su apropiación del apellido Saavedra es muy vasta, y pre- 
fiero dejarla ahora de lado. Más interés tiene para nosotros, en el marco de estas jornadas, la temática referente al cautiverio en Argel: la de los cinco años que permaneció el escritor en los baños de Hasán Pachá. También aquí la bibliografía es extensa y, en algunos casos, elaborada con enfoques ajenos a la literatura. En el brete de citas unos pocos ejemplos de obras que estimularon mi apetito de lector, escogería el sugestivo ensayo de Françoise Zmantar, «Cervantes y sus fantasmas de Argel», el libro de María Antonia Garcés, Cervantes in Algiers. A captive's Tale, sin olvidar, claro está, el imprescindible estudio de Emilio Sola y José F. de la Peña, Cervantes y la Berbería: todos ellos trazan un cuadro de los sufrimientos, heroísmo e incertidumbres de nuestro primer escritor frente a un mundo a la vez despótico y tolerante con la diversidad, un mundo que le fascinaba y le repelía, y que dejó una huella indeleble en su creación literaria, desde El trato de Argel hasta Persiles y Segismunda, cuyo comienzo - el primer párrafo del primer capítulo de la Primera Parte- le retrotrae a la experiencia traumática de los «baños»:

Voces daba al bárbaro Corsicurbo a la estrecha boca de una profunda mazmorra, antes sepultura que prisión de muchos cuerpos vivos que en ella estaban sepultados...

Una mera ojeada al conjunto de la obra cervantina nos muestra la reiteración casi obsesiva del tema del cautivo. Puro «taller de existencialidad», por tomar el título de este ciclo; pero algo más. Lo que Cervantes sufrió y las dudas que le acosaron, lo sabemos. Pero lo que pudo aprender en aquel universo abigarrado y complejo en el que se movían los cautivos, en el seno de una sociedad heterogénea en la que confluían todas las lenguas y culturas del Mediterráneo, sigue siendo un misterio. El salto de la narrativa europea renacentista a la invención del Quijote tiene, como vamos a ver, precedentes orientales y Américo Castro apuntó ya a ello en el capítulo dedicado al Libro de buen amor en España en su historia:

Para explicar esa radical estructura del libro máximo de la literatura española no acudiría hoy, sino muy cautelosamente, al pensar del Renacimiento, y pondría, en cambio, mayor acento en la interna continuidad de la existencia hispánica y en los años vividos por Cervantes en tierras de moros.

Aplaudamos el fino olfato de don Américo: su observación da en el blanco. Resulta incitante establecer un paralelo entre los procedimientos literarios del Quijote - una creación, insistimos, absolutamente original e irreductible a todo modelo previo- y los del relato de Sahrazad, cuajados en los manuscritos que se conservan de Las mil y una noches. No voy a hablar aquí de influencias directas - Cervantes no es Cide Hamete y no conocía el árabe-, sino de esa «polinización» por las llamadas por las botánicas «autopistas de viento» que operó durante siglos en el ámbito mediterráneo: primero en la Península, con El conde Lucanor y Kalila y Dimna; luego en la Italia de Boccaccio; y, un siglo después de la Primera Parte del Quijote, tras la traducción del relato de Sahrazad por Antonio Galland: bastaría citar los nombres de Potocki, Beckford y la utilización paródica de aquél en el Cándido de Voltaire.

Como sabemos, Las mil y una noches no tiene autor. Una azarosa y modificable concatenación de relatos configura un libro infinito, inconcluso. Cada lector, adaptador o traductor puede modificarlo a su guisa, quitarle o añadirle párrafos con entera libertad. 
Al no haber autoría, sólo transmisión, no hay autoridad. Tal vez la enseñanza más perdurable de una obra, que se sitúa en los antípodas de los textos fundadores de las religiones monoteístas, sea la de concedernos la posibilidad de elegir nuestras propias historias y sueños. Sus personajes se muestran siempre ansiosos, como en el Quijote, de escuchar relatos e historias, buscan manuscritos perdidos, conceden una gran importancia a lo escrito. En el relato-marco que abarca los demás, se nos dice que Sahrazad tenía una biblioteca de más «de mil volúmenes referentes a la historia de los pueblos extinguidos, de los antiguos reyes y de los poetas». Esto es: antes de narrar, aparece como un personaje narrado, que convierte los libros por ella leídos en un relato oral con el que reduce noche tras noche al monarca. Sus historias se abren con lo que Abdelfarah Kilito denomina el protocolo del comienzo: «se cuenta que» (yunka), o bien, «me he enterado» (balaghini) sin mencionar su origen ni a quien las escribió. Más significativo aún: nadie busca al autor de los relatos, sino a quienes los poseen. Y estos relatos se incrustan dentro de otros, se ramifican y crean un diagrama arbóreo, un verdadero laberinto en el que el narrador es narrado antes de convertirse de nuevo en narrador, creando así un prodigioso ejercicio de libertad interpretativa y de relativismo moral inexistente en la cultura occidental cristiana anterior a Cervantes. Como dijo bellamente Walter Benjamin, «el laberinto es la patria de los que dudan».

Los puntos de contacto entre Sahrazad y sus narradores narrados con «el primer autor», «los autores que sobre este caso escriben», Cide Hamete Benengeli y su poco fiable traductor morisco son numerosos: el recurso del manuscrito hallado; la causalidad narrativa, que podemos llamar acelerada, en «La gota de miel» de Las mil y una noches y el episodio protagonizado por Maritornes, don Quijote, el arriero, Sancho y el cuadrillero de la Santa Hermandad en el cap. XVII de la Primera Parte; el procedimiento del relato alternado, con el paso de un héroe a otro, como en «Nur Al Din y su hermano Sams Al Din» (noches 19-24) — «esto es lo que se refiere a [...] sea aquí lo que hace referencia a [...]-, procedimiento que hallamos en Cervantes cuando los dos protagonistas se separan $y$, mientras don Quijote permanece en el palacio de los duques, Sancho parte a gobernar la ínsula Barataria. Asimismo sugerente es el paralelo entre «El caballero de ébano» en las noches 357-371, y la burla cruel del episodio de la cueva de Montesinos. La lista de coincidencias es larga y la detengo aquí.

Volvamos ahora a la sagaz y aguijadora lectura cervantina de don Américo:

Sin que podamos mencionar ahora todos los estímulos incitantes presentes en el Quijote, es evidente que la palabra (tanto escrita como hablada) desempeña una función primordial. Sorprende que Unamuno, tan buen iluminador de ciertos aspectos del Quijote, no se diera cuenta de la función que aquí desempeñan los libros. Don Quijote vivista una imprenta porque «deseaba saber cómo fuese» (II, 62). Don Quijote y don Diego poseen bastantes libros; se emiten juicios sobre su valor y sobre el de sus traducciones; algunos son hallados en maletas olvidadas; hay quienes escriben libros, están escribiéndolos o piensan hacerlo, en serio o burlescamente. El Quijote es una contextura de vivencias de lecturas caballerescas, pastoriles, romancescas o históricas [...]. Nada de ello es azar ni elemento decorativo o redundante. Cervantes sentía la obsesión de la palabra escrita, poética, docta o religiosa, e inyecta su savia incitante en unas vidas que de otro modo no hubiesen salido de su inerte insignificancia. 
Aquí no se trata del cuento o la vida, como en Las mil y una noches, sino de algo menos dramático y acuciante, pero esencial. Los personajes del Quijote vertebran sus vidas en la lectura o condición de relatos impresos u orales, confunden, como el hidalgo manchego, la imaginación y la realidad, y configuran ésta en función de aquélla. Cito:

Al Hidalgo manchego le afecta en grado extremo la lectura de aquellos libros, pero no es menos cierto que fenómenos de la misma índole acontecen a otros personajes [...]. Según el Cura, los volúmenes leídos por Alonso Quijano «le habían vuelto el juicio» (I, 32); el Ventero siente de otro modo, porque a él le ocasionan otros efectos.

Cada cual habla de la feria según le va en ella, y el libro se incorpora a la experiencia vital de cada uno. La Ventera quisiera que la lectura se prolongara por muy otros motivos: «Nunca tengo buen rato en mi casa sino aquel que vos estáis escuchando leer; que estáis tan embobado, que no os acordáis de reñir por entonces.» Maritornes reduce el libro a su imagen de «la señora debajo de los naranjos abrazada con su caballero», lo cual le sabe a «cosa de mieles». La hija de la Ventera, una recatada doncella, cuya sensibilidad se afinó con la lectura de novelas pastoriles, no gusta «de los golpes de que mi padre gusta, sino de las lamentaciones que los caballeros hacen cuando están ausentes de sus señoras.

El Ventero se opone a que sus libros sean quemados; cree de tal modo en su verdad, que Dorotea susurra al oído de Cardenio: «Poco falta a nuestro huésped para hacer la segunda parte de don Quijote.»

Como los manuscritos buscados en Las mil y una noches, su valor no se cifra en su consiguiente descubrimiento y depósito en alguna biblioteca, sino, como observa Castro, «en su vitalidad contagiosa». La lectura o escucha de relatos «contamina» y nos transforma en otros. Pues Cervantes da un paso más respecto a la galaxia de relatos que fecundó la literatura medieval y renacentista europea: crea personajes «transitivos», cuyo carácter se modifica conforme a las circunstancias y experiencias personales. El tema ha sido ampliamente debatido a lo largo del pasado siglo, desde los formalistas rusos y el Círculo de Praga hasta los ensayos recientísimos de dos grandes novelistas, como Kundera y Fernando del Paso.

Creo que los mejores lectores del Quijote en lengua española - esto es, los que fueron capaces de percibir su novedad en la historia del género novelesco desde un punto de vista artístico, en el que forma, estructura y contenido van indisolublemente unidos, fueron Azaña, Borges y Américo Castro.

Hablar de vida y de literatura en el Quijote no nos aclara la radical novedad de su invención. Cervantes, al crear esta extraordinaria estructura artística de su novela, nos muestra que, cuando la vida entra en la literatura, se convierte a su vez en literatura y hay que juzgarla como tal. Autores - así, en plural-, personajes y lectores de la obra carecen de estatuto fijo. Podemos pasar de una instancia a otra. La semilla hindú, iraní y árabe de Sahrazad germinó en el territorio de La Mancha y creó un árbol de ramificación infinita. Gracias a la oportuna intervención del Quijote apócrifo de Avellaneda, el don Quijote y Sancho de la Segunda Parte tienen neta conciencia de su doble proyección exterior y esa dualidad abre el camino a la galería de voces y de espejos que es a fin de cuentas la novela cervantina y la de su fecunda descendencia de los cuatro últimos siglos. 